\title{
Kaotik bir hareket videosunun yapay sinir ağları ile modellenmesi
}

\author{
Murat Erhan ÇíMEN',*, Sezgin KAÇAR ${ }^{1}$, Emre GÜLERYÜZ², Bilal GÜREVİN², \\ Akif AKGÜL ${ }^{1}$
}
${ }^{1}$ Sakarya Üniversitesi Teknoloji Fak. Elektrik- Elektronik Müh. Böl., Esentepe kampüsü, Sakarya. ${ }^{2}$ Sakarya Üniversitesi Fen Bilimleri Enstitüsü, Esentepe kampüsü, Sakarya.

Geliş Tarihi (Recived Date): 13.08 .2018

Kabul Tarihi (Accepted Date): 24.10.2018

\section{Özet}

Bu çalışmada kaotik bir hareketin modellenerek tekrardan oluşturulabilmesi için yapay sinir ağları kullanılmıştır. Kaotik sinyaller, doğal ilişkiler, iletişim, şifreleme, finans, să̆lık gibi birçok alanda ortaya çıkabilir. Yapay sinir ă̆ları, bulanık model, hammerstein gibi modeller bu tip sinyalleri öngörmek ve form halinde matematiksel olarak hareketi modellemek için kullanılabilir. Bu hareket ikinci dereceden bir ters sarkacın hareketi, bilardo masasindaki topların hareketleri veya bu tip sistemlerin faz diyagramlart da olabilir. Burada ise en temel olan Lorenz kaotik hareketinin faz diyagramı tercih edilmiştir. Ardışık görüntülerde izlenen nokta veya nesnenin görüntü pozisyonu görüntü işleme teknikleri ile belirlenmiştir. Bu görüntülerden elde edilen konum bilgisini kullanarak, NAR yapısı olan yapay sinir ağları geri yayılım algoritması ile eğitilmiştir. Bu NAR yapısı iki giriş ile iki çıkış olarak oluşturulmuş ve ilk katmanı 20, ikinci katmanı 10 ve üçüncü katmanı da 2 nöron içermektedir. Ardından bu yapay sinir ağları test edilerek tekrardan kaotik hareket videosu elde edilmeye çalışılmıştır. Sonuç olarak, bazı kaotik işaretlerin, ardışıl görüntülerin veya videoların matematiksel olarak modellemek yerine yapay sinir ağları ile modellenip tekrardan üretilebilmesi sağlanmıştır.

Anahtar kelimeler: Kaos, kaotik sistemler, yapay sinir ağları, görüntü işleme.

\footnotetext{
* Murat Erhan ÇİMEN, muratcimen@ sakarya.edu.tr, https://orcid.org/0000-0002-1793-485X Sezgin KAÇAR, skacar@sakarya.edu.tr, https://orcid.org/0000-0002-5171-237X Emre GÜLERYÜZ, emre.guleryuz1@ ogr.sakarya.edu.tr, https://orcid.org/0000-0001-6198-3571 Bilal GÜREVİN, bilalsau@gmail.com, https://orcid.org/0000-0003-4035-2759

Akif AKGÜL, aakgul@ sakarya.edu.tr, https://orcid.org/0000-0001-9151-3052
} 


\title{
Modelling of chaotic motion video with artificial neural networks
}

\begin{abstract}
In this study a chaotic motion is modelled using artificial neural networks can be created again. Chaotic signals can occur many fields like natural affairs, communication, encryption, finance, health. Artificial neural networks, fuzzy models, hammerstein model can be used to predict these types of signals as well as to provide a mathematical form to be modelled. As an example of the motion that will be modelled in this study, there may be movement of an second order inverted pendulum, movements of balls on a billiard table, or phase diagrams of such systems. However, the phase diagram of the most basic Lorenz chaotic motion is preferred. The image position of the point or object that is followed in sequential images are determined by image processing techniques. By using the position information obtained from these images, they are trained with backpropagation algorithm to artificial neural networks, which is NAR structure. NAR structures is constructed with two inputs, two outputs. Its first layer contains 20 neurons, second structure contains 10 neurons and third structure contains 2 neurons. Subsequently, NAR artificial neural networks were tested to try to get chaotic motion videos again. As a result, some chaotic signals, sequential images, or videos can be modelled with artificial neural networks instead of being mathematically modelled and reproduced.
\end{abstract}

Keywords: Chaos, chaotic systems, artificial neural networks, image processing.

\section{Giriş}

Kaos başlangıç şartlarına aşırı derecede duyarlı olup gürültü gibi görünen fakat genel çerçevede bir düzenin olduğu davranışlardır. Dolayısıyla son yıllarda bu tip sistemlerin işaretleri, deterministik ve rastgele işaretler arasında kalmış ve ümit vaat ettiği için bu tip davranışların tespit edilmesi üzerine çalışmalar yapılmaktadır [1-4]. Bu anlamda ilk olarak bir meteorolog olan Lorenzin hava durumunun tahmini için topladığı veriler ile hava durumunu modellemesi ile başlamıştır. Ardında türbilans hareketleri için farklı bilim insanları bu konu üzerine çalışmaya devam etmişlerdir. Bu tip sistemlerin genel özelliğine bakıldığında düzgün bir dinamiğe sahip olmasına rağmen başlangıç durumuna çok duyarlı olan doğrusal olmayan sistemlerdir. Bu kaotik davranışlar ekonomide, biyolojide, kimyada, bilişimde, tıpda, mühendislik vb alanlar karşılaşılabilmektedir [3, 5].

Kaotik işaretler, başlangıç şartlarına çok hassas, deterministik, gürültü sinyali veya benzeri güç spektrumuna sahip, genliği ve frekansı bilinmeyen ancak sınırlı bir alan içerisinde değisen karmaşık davranışlar göstermektedir [1].

Kaotik işaretler elde edildikten sonra verilere uygun bir matematiksel model ile ifade edilebilmektedir [6]. Bu direk olarak nonlineer bir denklem formatında olabileceği gibi bulanık modelle, yapay sinir ağları veya volterra serileri gibi farklı modelleme teknikleri ile bu tip davranışlar modellenebilmektedir [7]. Bu bağlamda bu çalışmanın yapılmasının amacı, matematiksel olarak modeli oluşturulamayan bir nesnenin hareket videosundan hareketinin modellenmesidir. Bunun için ilk olarak videodaki nesnenin 
konum bilgileri görüntü işleme teknikleri ile belirlenmesi, ikinci adımda ise yapay sinir ağ 1 tabanlı bir model oluşturulması ve bu modelin görüntüden elde edilen verilere bağlı olarak eğitilmesidir. En sonunda da bu hareketin tekrardan yapay sinir ağı modeli üzerinden yaklaşık olarak aynı davranışı elde edebilmektir.

Kaos alanındaki sıçrama yaratan ilk keşiflerden biri, 1963 yılında Edward Lorenz tarafından yapılmıştır [1, 3, 8, 9]. Lorenzin önerdiği bu model başlangıç koşullarında çok küçük değişiklikler bile sistem çıkışında çok büyük farklara neden olduğu görülmüştür. Farklı bir başlangıç noktasından başladığında önceki çözümden üstel olarak farklı zaman aralıklarında uzaklaşmaktadır. $\mathrm{Bu}$ ise faz diyagramlarıyla, çatallaşma diyagramı veya Lyapunov ile daha belirgin şekilde görülebilmektedir [1013]. Bunun için ilk önce sisteme uygun dinamik bir model belirlenmesi gerekmektedir. Sisteme uygun bir modelin belirlenmesi bazen zor olabilmektedir. Son zamanlarda bilgisayar sistemlerinin gelişmesi ile sistemden elde edilen dinamikleri de ifade edebilen farklı tipte model türleri ile sistemler modellenebilmektedir. $\mathrm{Bu}$ tip farklı dinamiğe sahip sistemlerin modellenmesinde pek çok yöntem kullanılmaktadır [7]. Maguire ve ark. kaotik bir sinyalin bulanık modeller ile ifade edilebildiğini göstermişlerdir [14]. Kuo ve arkadaşı kaotik bir zaman serisininde öngörü yapabilmek için yapay sinir ağlarını kullanmışlardır [15]. Gómez-Gil ve ark. da uzun süreli bir kaotik sinyalin yapay sinir ağları ile modellenmesi üzerinde çalışmışlardır [16]. Fırat ise yapmış olduğu çalışmada kaotik davranış sergileyen depremlerin yapay sinir ağları ile modellenmesi üzerine çalışma yapmıştır [17]. Hanbay yapmış olduğu çalışmada kaotik bir davranış sergileyen Chua Devresinin Yapay sinir ağı ile modellemesini gerçekleştirmiştir [18]. Panahi ve ark. yapmış olduğu çalışmada da kendi önerdikleri özel bir yapay sinir ağı modeli ile epilepsi hastalığının modellenmesini yapmışlarıdır [19]. Bir nesnenin konumunu bulmaya yönelik olarak çok fazla çalışma yapılmıştır. Köker ve ark. ise hareketli nesnenin konumunun tespiti için kameradan sürekli veriler alarak görüntüden kendi belirledikleri öz nitelikleri ile karşılaştırarak cismin konumunu bulmaya yönelik çalışma yapmışlardır [20]. Karakaya ve ark. İse görüntü üzerinde HOG algoritması tekniğini FPGA üzerinde uygulayarak gerçek zamanlı olarak nesne tanıma gerçekleştirmişlerdir [21]. Solak ve ark. ise findık meyvesinin tespiti ve sınıflandırılması için öznitelik ve k-means algoritmalarını kullanmışlardır [22]. Varol ve ark. ise farklı yüz tanıma algoritmalarını tanıtmış ve PCA algoritmasında uygulama yapışlardır [23]. Çelik ise yüksek lisans tezinde görüntü işleme ve yapay zeka ile avuç için tanınmasını gerçekleştirmiştir [24]. Bu çalışmada da videosu çekilen bir nesnenin hareketinin modellenmesi için ilk olarak nesne tanıma yapılmıştır. 2. Bölümde yapılan bu işlemde ilk olarak videonun her bir karesindeki nesneyi bulabilmek için nesnenin görüntü karelerindeki özniteliklere bakılarak cisim belirlendi ve ardından belirlenen cisimlerin konum bilgileri ağırlık merkezine göre bulundu. 3. Bölümde ise yapay sinir ağları hakkında genel bir bilgi verilmiş olup Nonlineer Autoreggressive Neural Network (NAR) yapısındaki yapay sinir ağlarına cismin konum bilgileri eğitilmiştir. Ayrıca bu bölümde gerçek ile yapay sinir ağları ile modellenmiş olan kaotik videodan elde edilen verilerin eğitilmesine yönelik bir örnek verilmiştir. 4. Bölümde ise sonuçlar karşılaştırılarak bu yönteminde uygulanabileceği tartışılmıştır.

\section{Görüntüdeki özniteliklerden cismi belirleme ve konum bulma}

Videolar birçok görüntünün birleşiminden oluşmaktadırlar. Dolayısıyla video üzerindeki herhangi bir nesnenin takibi görüntüde bulunan nesnenin konumunun 
belirlenmesi ile sağlanmaktadır. Bunun için resim üzerinde bulunan istenen resim özellikleri aranarak yapılmaktadır. Örneğin görüntü eşleme, şablon eşleme, yönlü gradyan histogramı, HAAR kaskat sınıflandırısı, temel bileşenler analizi, bağımsız bileşenler analizi, destek vektör makineleri, doğrusal diskriminant analizi, elastik demet grafik işaretleme gibi pek çok teknik bulunmaktadır [23, 25].

Bu çalışmada ise görüntü alındığında ilk olarak gürültünün azaltılması için 3x3 medyan filtre kullanılmıştır. Belirlenen maske görüntü üzerinde gezdirilmektedir. Görüntüde kaydırılan maskenin piksel değeri ile görüntünün eşleşen pikselleri çarpılır. Ardından bu değer maskenin görüntü üzerindeki konumuna göre pikselin yeni değeri olmaktadır.

Belirlenen işleme bağlı olarak Eşitlik (1) kullanılarak görüntü renkli formdan gri forma dönüştürüldü. Ardından Eşitlik(2) kullanılarak bir eşikleme işlemine tabii tutulur. $\mathrm{Bu}$ sayede görüntü 2 seviyeye quantalanması sağlanmış oldu. Bu işlemler Şekil 1a ve Şekil 1 b'deki gibi yapılmıştır.

$$
\begin{aligned}
& f(x, y)=\frac{f(x, y, 1)+f(x, y, 2)+f(x, y, 3)}{3} \\
& I(x, y)=\left\{\begin{array}{cc}
0 & f(x, y) \leq T \\
255 & f(x, y)>T
\end{array}\right.
\end{aligned}
$$

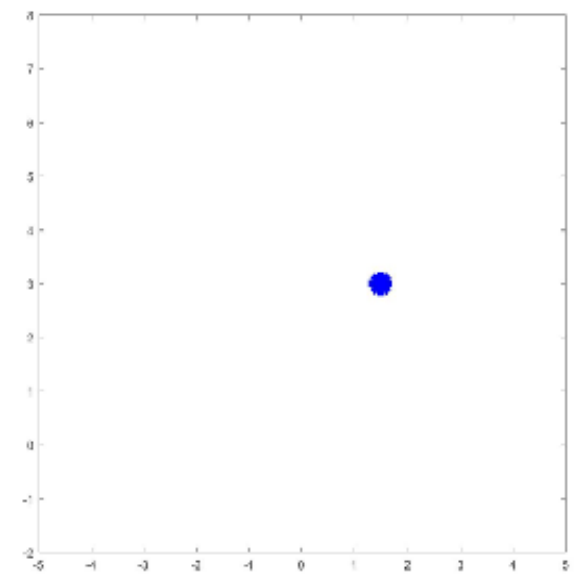

Şekil 1.a Resmi gri forma dönüştürme

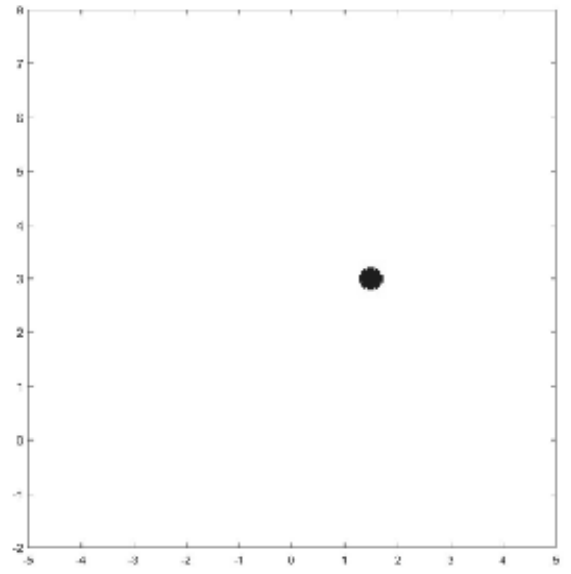

Şekill.b Resmi eşikleme

Görüntü üzerinde cisimlerin yerini belirlemek için en kolay yöntemlerden birisi kenar belirlemektedir. Elde edilen görüntü için gradyen Eşitlik (3) ile ifade edilebilir.

$$
\nabla \mathrm{I}(\mathrm{x}, \mathrm{y})=\left[\begin{array}{l}
\mathrm{g}_{\mathrm{x}} \\
\mathrm{g}_{\mathrm{y}}
\end{array}\right]
$$


Eşitlik (3)'de verilen türev hem yatay eksene hem de dikey eksene göre alınmış bir türevi ifade etmektedir. Dolayısıyla bunların hesaplanması için Eşitlik (4)'deki maskeler ve Eşitlik (5)'deki denklemler kullanılmaktadır.

$$
\begin{aligned}
& \mathrm{W}_{\mathrm{x}}(\mathrm{i}, \mathrm{j})=\left[\begin{array}{ccc}
-1 & -2 & -1 \\
0 & 0 & 0 \\
1 & 2 & 1
\end{array}\right] \quad \mathrm{W}_{\mathrm{y}}(\mathrm{i}, \mathrm{j})=\left[\begin{array}{ccc}
-1 & 0 & 1 \\
-2 & 0 & 2 \\
-1 & 0 & 1
\end{array}\right] \\
& \mathrm{g}_{\mathrm{x}}=\sum_{\mathrm{j}} \sum_{\mathrm{i}} \mathrm{I}(\mathrm{x}+\mathrm{i}, \mathrm{y}+\mathrm{j}) \mathrm{W}_{\mathrm{x}}(\mathrm{i}, \mathrm{j}) \\
& \mathrm{g}_{\mathrm{y}}=\sum_{\mathrm{j}} \sum_{\mathrm{i}} \mathrm{I}(\mathrm{x}+\mathrm{i}, \mathrm{y}+\mathrm{j}) \mathrm{W}_{\mathrm{y}}(\mathrm{i}, \mathrm{j})
\end{aligned}
$$

Gradyanın büyüklügü için Eşitlik (6) kullanılabilir.

$$
\mathrm{g}(\mathrm{x}, \mathrm{y})=|\nabla \mathrm{I}(\mathrm{x}, \mathrm{y})|=\sqrt{\mathrm{g}_{\mathrm{x}}^{2}+\mathrm{g}_{\mathrm{y}}^{2}}
$$

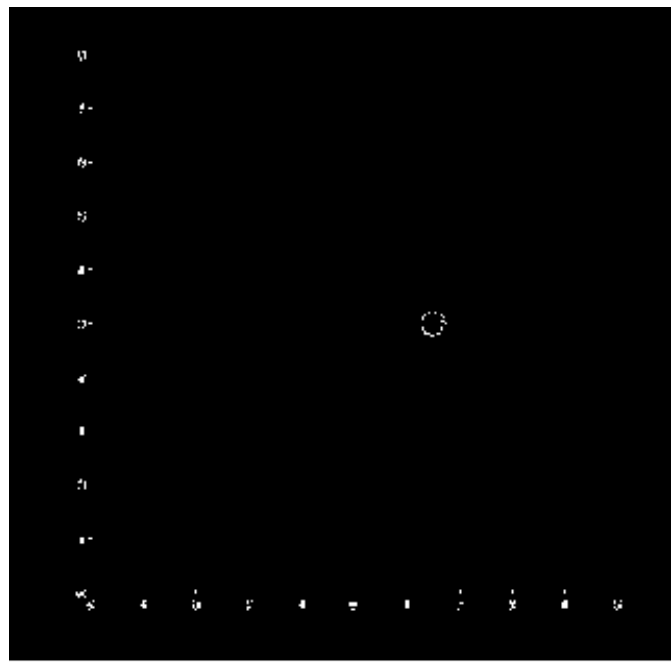

Şekil 2a. Kenar bulma.

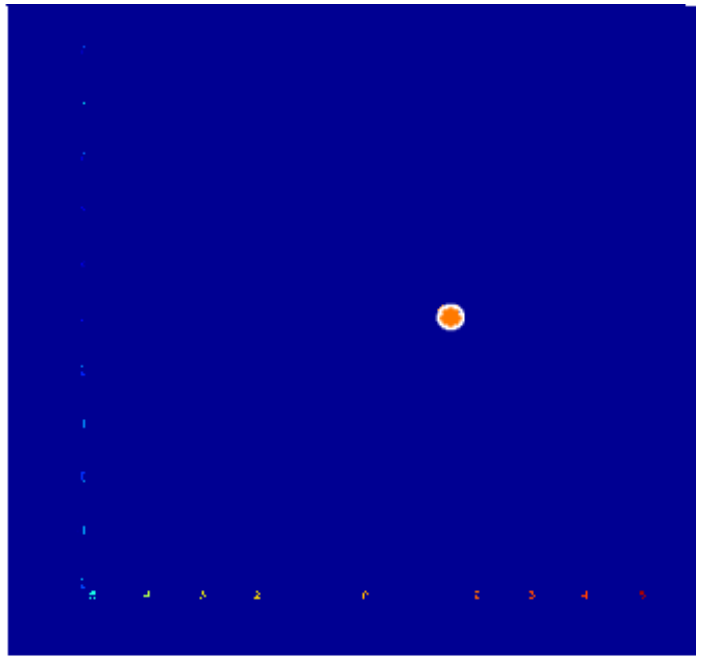

Şekil 2b. Delikleri numaralandırma.

Kenarları elde edilen görüntü Şekil 2a'deki gibi elde edilmiştir. Fakat görüntü içerisinde aranan cismin belirlemek için görüntü üzerindeki her bölgeye farklı bir değer ataması yapılarak Şekil 2b'deki gibi görüntünün bölüntülenmesi sağlanmış oldu. Bununla birlikte görüntü üzerinden takip edilecek olan nesnenin bir takım özellikleri bulunmaktadır. Bunlara örnek olarak;

- Alanı

- Çevre uzunluğu

- Çap1

- Kapanılan en küçük dikdörtgen

- Ağırlık merkezi

- Gri parlaklık seviyesi (maksimum,mininum,ortalama) 
- Momentleri

- Cisimdeki içindeki delik sayısı

verilebilir. Bu çalışmada ise Eşitlik (7)'de kullanılan ağırlık merkezi ve Eşitlik (8)'de kullanılan alan özellikleri kullanıldı. Ortaya çıkan cismin alanına göre nesnenin ağırlık merkezi belirlenmektedir.

Ağırlık_Merkezi $=\left(\frac{1}{\mathrm{n}} \sum_{\mathrm{x}} \mathrm{x}, \frac{1}{\mathrm{n}} \sum_{\mathrm{y}} \mathrm{y}\right)$

Alan $=\sum_{\mathrm{x}} \sum_{\mathrm{y}} \mathrm{I}(\mathrm{x}, \mathrm{y})$

Bu işlem ile takip edilmesi istenen cismin ayırt edici özelliği diğer cisimlerden ayrılarak istenen nesnenin takip edilmesi sağlanabilmektedir. Eğer görüntüde birden fazla cisim olsa idi daha fazla ayırt edici özellik olması için daha fazla öznitelik çıkarmak gerekebilirdi. Bu çalışmada ise videoda takip edilmek istenen nesnenin görüntü üzerindeki x ve y konumları alınarak kullanılmak üzere hafızada saklanmıştır.

\section{Yapay sinir ağları ile hareket videosunun modellenmesi}

Yapay sinir ağı; sinir hücrelerinden oluşmuş olan insan beyninin sayısal dünyadaki uygulanabilir bir modelidir. Genel olarak bu model sinir hücrelerinin seri ve/veya paralel ve/veya katmanlı olarak birbirine bağlanmasına benzetilerek oluşturulmaktadır. Ayrıca çıkışının ise aktive edilmesi gibi özelliklerini temsil edebilmesidir. $\mathrm{Bu}$ temsil edebilme özelliği sayesinde yapay sinir ağları modelleme, sinıflandırma, görüntü tanıma, öngörme, yol planlama gibi farklı amaçlarla mühendislik, tıp veya finans gibi farklı alanlara uygulanabilmektedir. Özellikle doğrusal ve/veya doğrusal olmayan, basit ve/veya karmaşık, tek ve/veya çok değişkenli veya zamanla değişen sistemlerin temsil edilebilmesinde, ölçülmesi zor veya imkânsız olan parametrelerin veya durumların kestirilebilmesi veya tahmin edilebilmesi gibi çok çeşitli amaçlarla modellemede kullanılmaktadır. Basitçe insan beyninin yapısını ve çalışma şeklini taklit eden yapay sinir ağları çok sayıdaki değişkenle çalışarak eldeki veriden öğrenebilme, bu verilere göre genelleme yapabilme gibi birçok önemli özellikleri bulunmaktadır. Dolayısıyla bu yapı kullanılarak herhangi bir sistem hakkındaki sınırlı bilgi ile giriş-çıkış ilişkilerine dayalı bir model üretilebilmektedir. Ayrıca eğitilmiş olan bir yapay sinir ağı modeli; değişken durumlara uyum sağlayabildiği ve genelleme yeteneği sayesinde bilinmeyen bir girişe karşılık sonuç üretebilmektedir. Şekil 3'de verilmiş olan yapay sinir hücresine bakıldığından genel olarak; giriş, çıkış, ağın ağırlıkları, birleşme fonksiyonu ve aktivasyon fonksiyonu olmak üzere 5 temel yapıdan oluşmaktadır. Çalışmasına bakıldığında ise yapay sinir ağlarına herhangi bir giriş uygulandığında; girişler düğüm noktasına gelirken belirli ağırlıkları ile çarpılmaktadır. Çarpımların sonucu bir birleştirme fonksiyonunda değerlendirilir, buradan elde edilen sonuç da aktivasyon fonksiyonu aktarılmaktadır. Aktive olan aktivasyon fonksiyonunun sonucu çıkışa aktarılmaktadır. Aktivasyon fonksiyonunun olmasının nedenleri; çıkan değeri belirli bir alanda sınırlamak ve özellikle ağın eğitilebilmesi için türevinin alınabilir bir fonksiyonu olmasidir. 


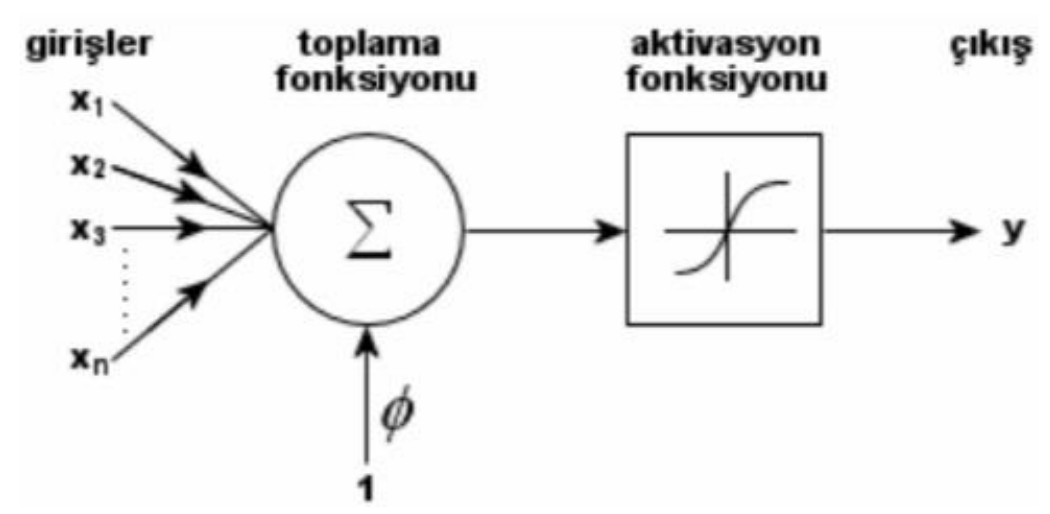

Şekil 3. Tek katmanlı YSA.

$$
\begin{aligned}
& \text { net }=\sum_{i=1}^{n} w_{i} x_{i}+\phi \\
& y=f(n e t)
\end{aligned}
$$

En basit hali ile verilen Şekil 3'deki YSA modeli Eşitlik (9)'daki denklem ile modellenebilir. Burada kullanılan aktivasyon fonksiyonu genellikle türevi alınabilen bir fonksiyon olan sigmoid fonksiyonu tercih edilmektedir. Bu tek katmanı YSA her ne kadar iyi olsa da kaotik bir sistemi modellemek için bu yeterli olmamaktadır. Bu nedenle içerisinde birden fazla katman eklenmiş olan bir yapı olan çok katmanlı yapay sinir ağı kullanılacaktır.

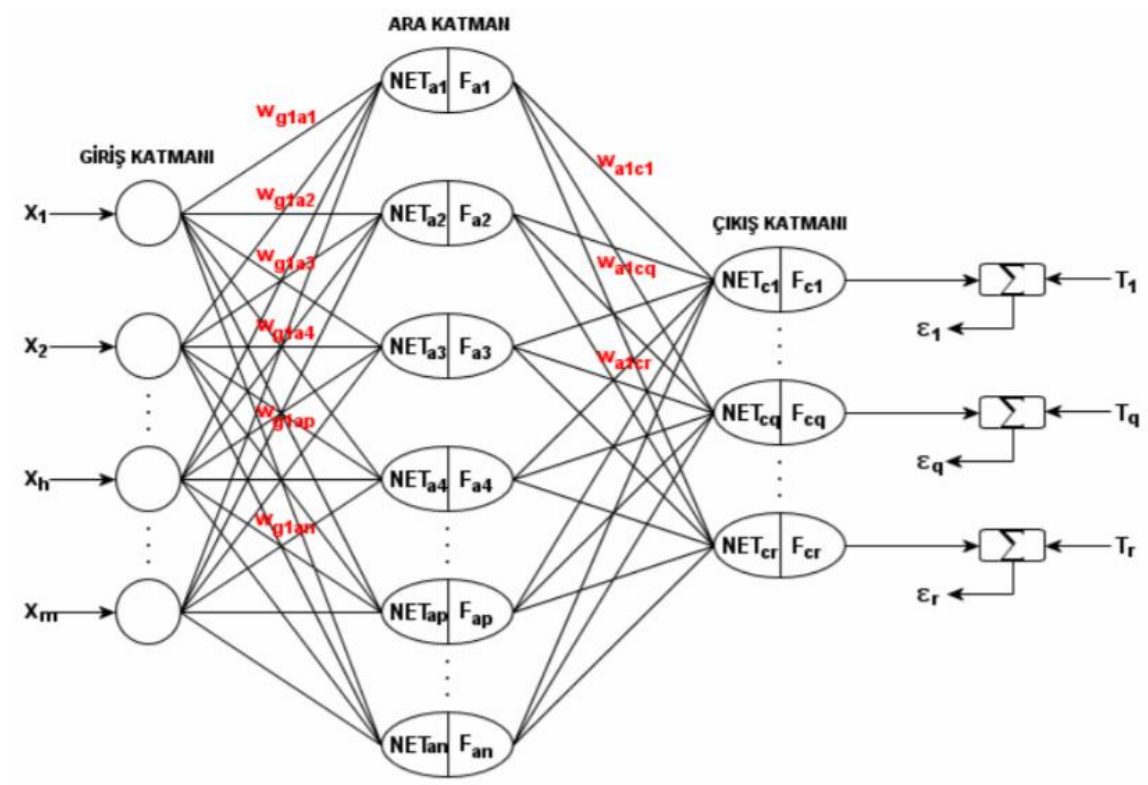

Şekil 4. Çok katmanlı YSA.

Şekil 4'de blok şekilde verilen Çok katmalı Yapay Sinir Ağları giriş katman, ara katman ve çıkış katmanlarından oluşmaktadır. Bu yapının matematiksel mantığı tek katmanlı yapıya çok benzemektedir. Lakin burada giriş katmanına gelen her bir giriş değeri ara katmanlara bir ağırlık ile çarpılarak ara katmandaki birimlere ulaşabilmektedir. Buraya ulaşan her bir birimin değeri ise belirli bir işlemden geçerek bir sonraki çıkış katmanın 
girişi olmaktadır. Bu işlemi matematiksel olarak ifade edildiğinde ara katmana gelen ağın değeri Eşitlik (10)'da verilmiştir. Buradan elde edilen değer Eşitlik (11)'deki aktivasyon fonksiyonu ile çıkış katmanının girişi olabilmektedir. Aynı şekilde buraya ulaşan her bir değer yine bir ağırlık ile çarpılıp Eşitlik (12)'deki gibi çıkış katmanının NET değerini belirlemektedir. Ardından tekrardan Eşitlik (13) aktivasyon fonksiyonu ile ağ çıkışı elde edilmektedir.

$$
\begin{aligned}
& \mathrm{NET}_{\mathrm{ap}}=\sum_{\mathrm{i}} \mathrm{w}_{\mathrm{gi}, \mathrm{ap}} \cdot \mathrm{x}_{\mathrm{i}} \\
& \mathrm{F}_{\mathrm{ap}}=\mathrm{f}\left(\mathrm{NET}_{\mathrm{ap}}\right) \\
& \mathrm{NET}_{\mathrm{cq}}=\sum_{\mathrm{i}} \mathrm{w}_{\mathrm{ai}, \mathrm{aq}} \cdot \mathrm{F}_{\mathrm{ai}} \\
& \mathrm{F}_{\mathrm{cq}}=\mathrm{f}\left(\mathrm{NET}_{\mathrm{aq}}\right)
\end{aligned}
$$

Yapay Sinir Ağlarının en temel mantığı bu olmakla birlikte bu yapıya çıkıştan birim geri besleme ekleyerek NAR (Nonlineer Autoregressive Neural Network) yapılabilmektedir. Bu çalışmanın muhtevası gereği girişler direk olarak çıkışların birim gecikmekli girişleri olduğu için bu yapı tercih edilmiştir. Bunun blok diyagramı da Şekil 5'de verilmiştir.

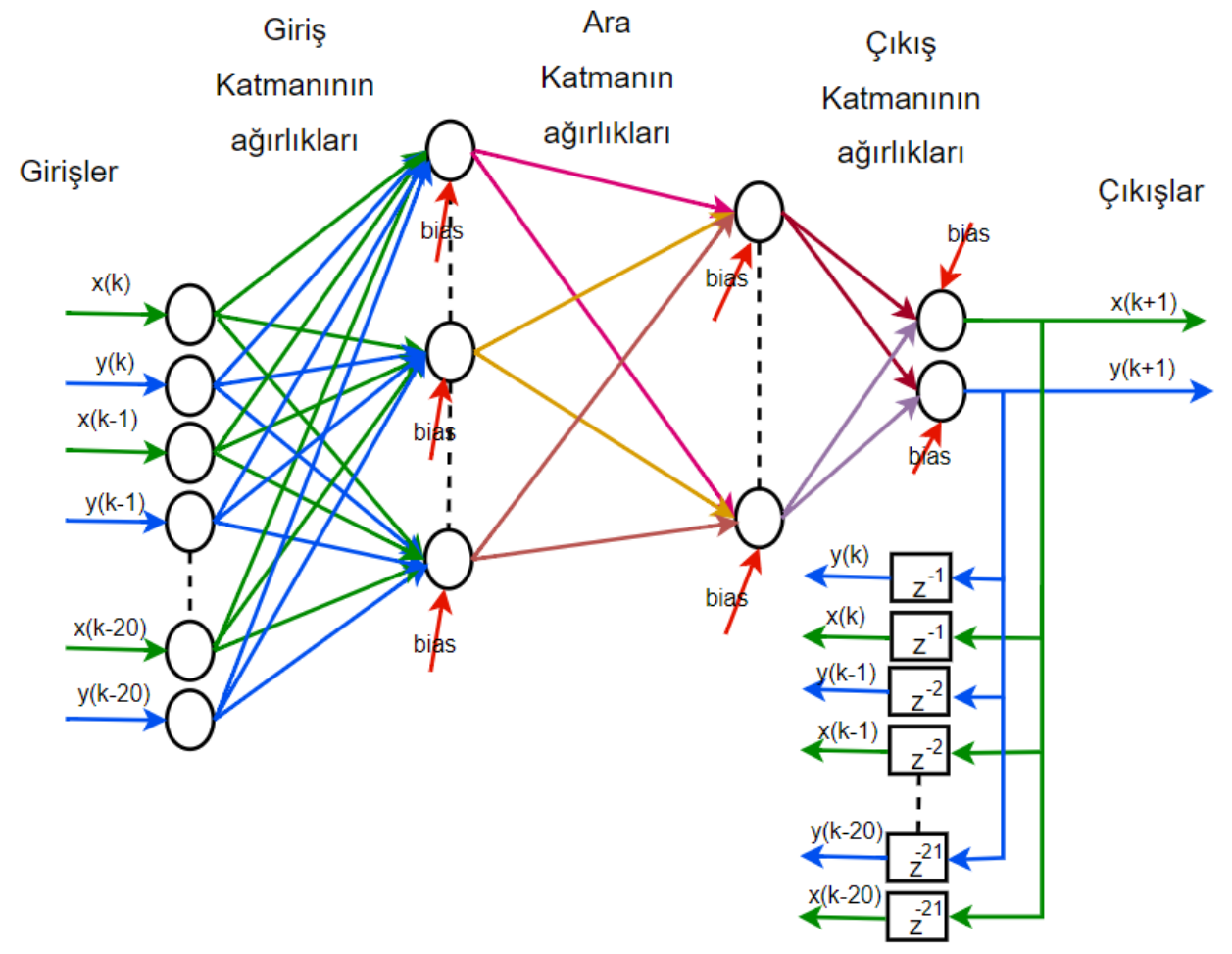

Şekil 5. Nonlineer autoreggressive neural network yapısı. 
Video üzerindeki nesnenin kaotik davranışın eğitilmesi için ilk önce videodan cismin ikinci bölümde anlatıldığı gibi konum bilgileri alınmıştır. Ardından bu konum bilgileri NAR yapısındaki YSA'ya verilmiştir. Matlab'da oluşturulan bu yapı Şekil 5'de verilmiştir. Burada YSA'nın ilk katmanı 20, ara katmanında 10 nöron ve çıkış katmanı 2 nöron olarak belirlenmiştir. YSA'nın eğitilmesi içinde Şekil 6'da verilen nntool'un içinde olan nntraintool özelliği kullanılmıştır. Bu ağın eğitilmesi için geri yayılım algoritması olarak Levenberg-Marquardt seçilmiştir. Geri beslemede ise konum sinyali olan her bir x ve y sinyalinin 20 birime kadar gecikmesi olarak seçilmiştir. Eğitim sonunda da adım sayısına göre performansını ifade eden ortalama kareli hatası Şekil 7'de verilmiştir.

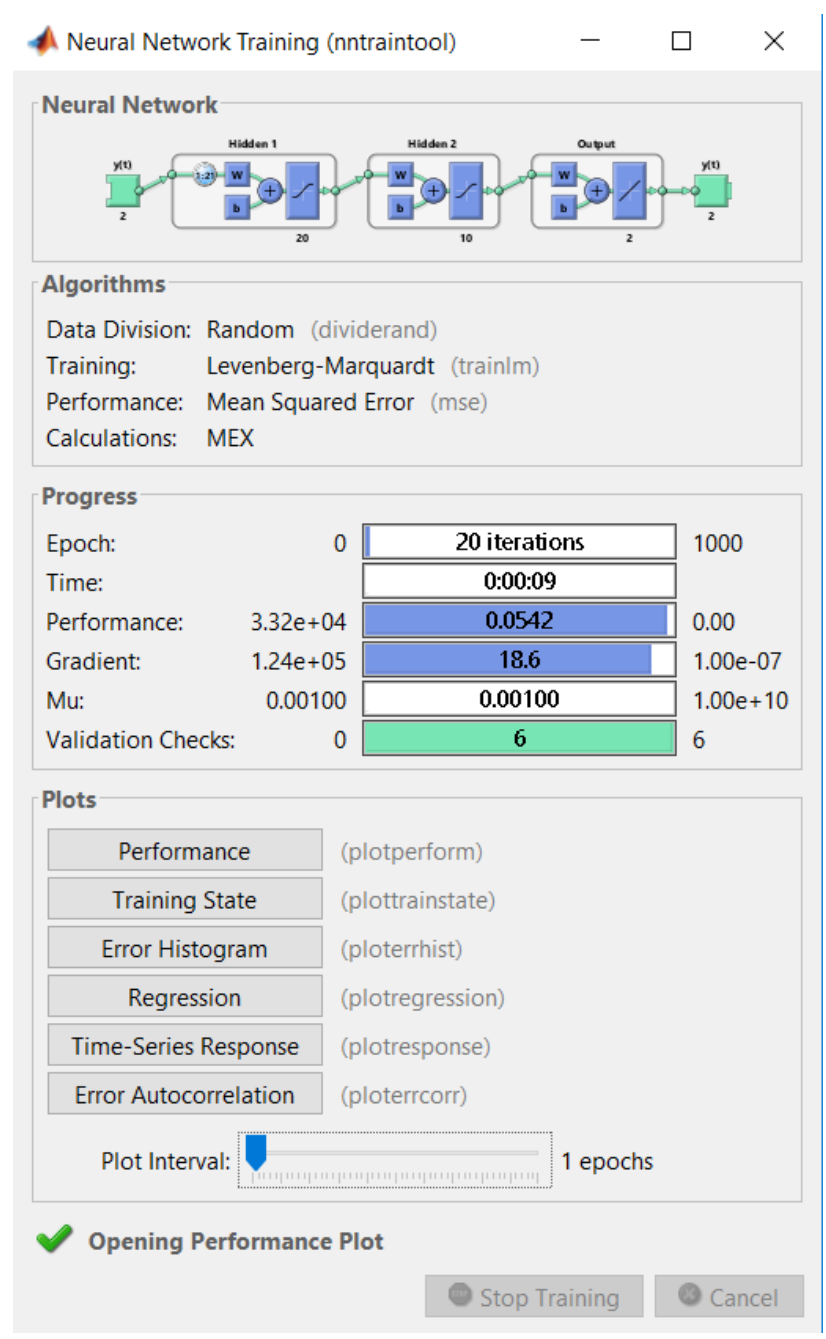

Şekil 6. YSA eğitim. 


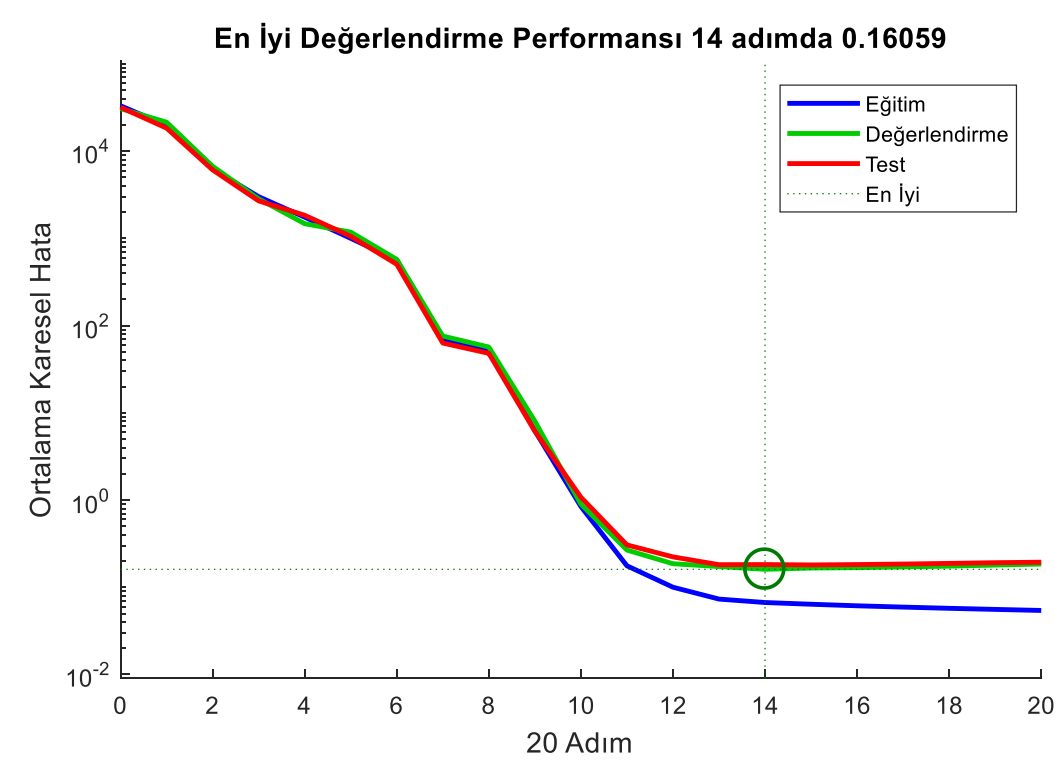

Şekil 7. YSA'nın performansı.

Sistem ile YSA modellinin çıkışları zamana bağlı olarak Şekil 8'de verilirken fazlara göre ise Şekil 9'da verilmiştir.

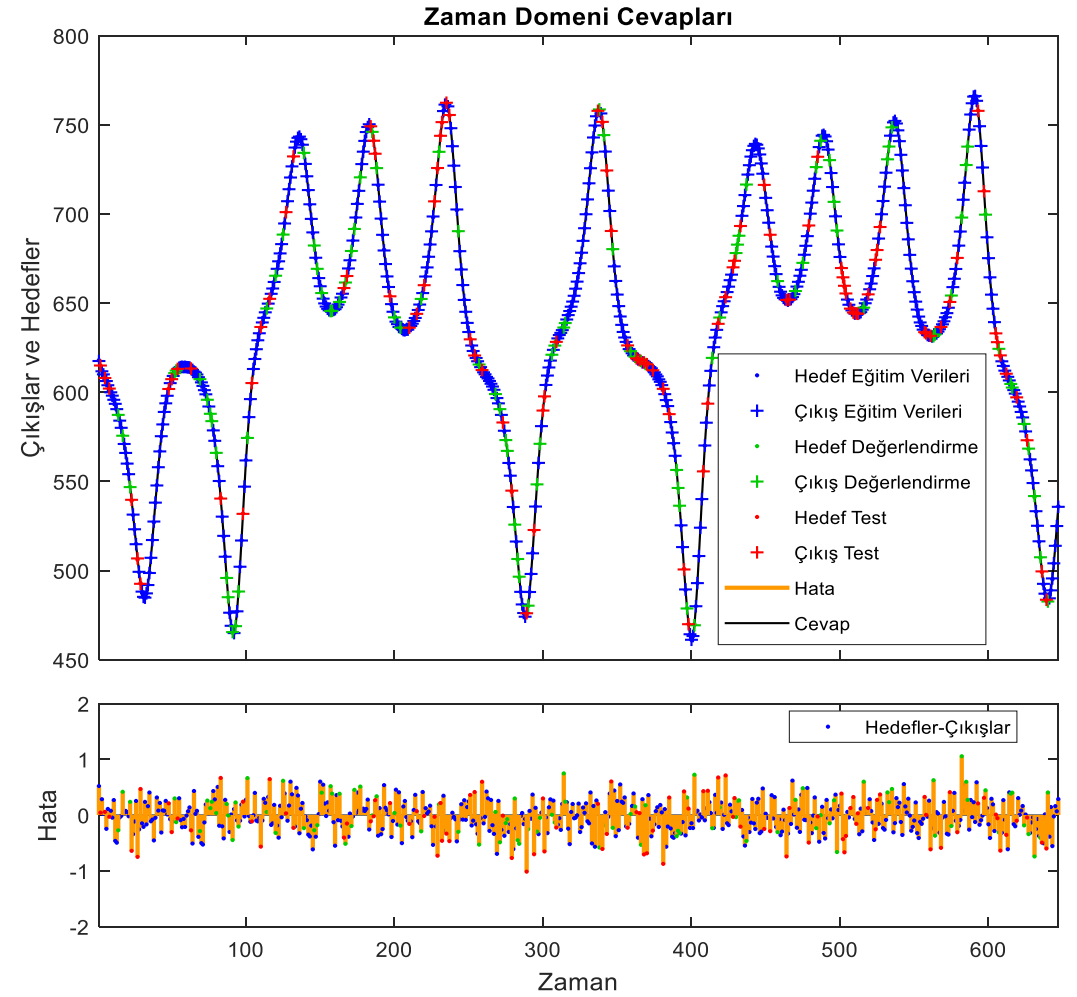

Şekil 8. Zaman bağlı YSA ve gerçek sonuçlar. 


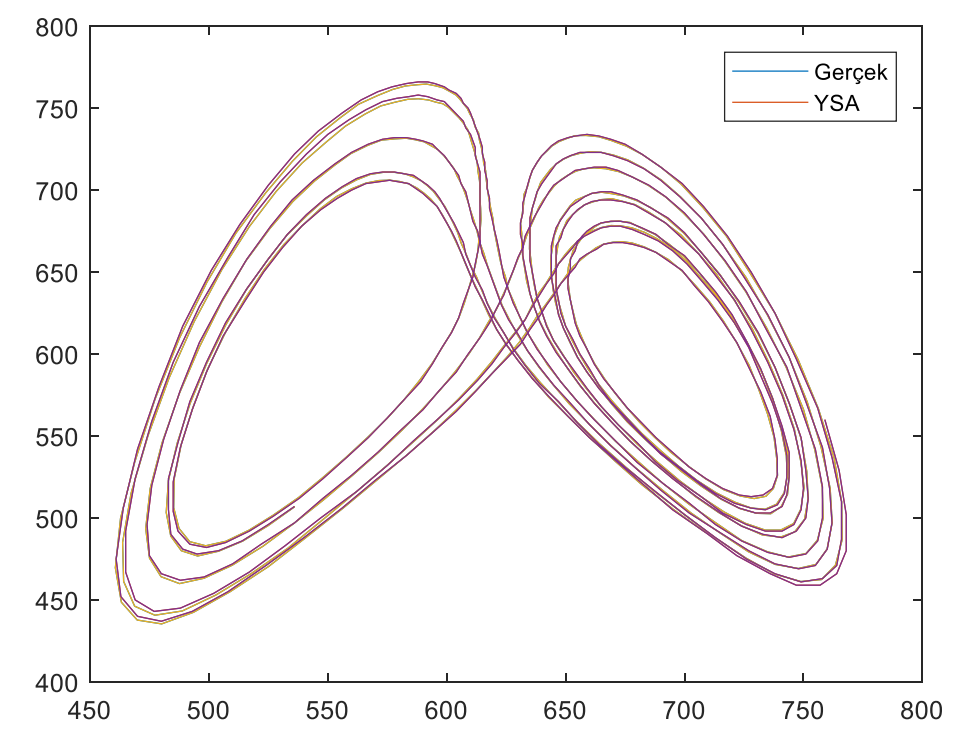

Şekil 9. Faza bağlı YSA ve gerçek sonuçlar.

\section{Sonuçlar}

$\mathrm{Bu}$ çalışmada kaotik bir davranış sergileyen bir cismin hareketi videodan elde edilmiştir. Bunun için takip edilmesi istenen cismin alan ve ağırlık merkezi içeren öznitelikleri kullanılarak konum bilgileri belirlenmiştir. Ardından alınan bu konum bilgileri NAR yapısındaki geri beslemeli bir yapay sinir ağına eğitilmiştir. Sonuç olarak matematiksel olarak ifade edilemeyen bir takım davranışların direk olarak video veya görüntü ile alınarak veri kümeleri üzerinden bu tip kaotik davranışlar modellenebilmektedir ve daha kısa sürdügü görülmüştür. Diğer taraftan elde edilen verilere göre matematiksel bir denklem sistemi önerilebilirdi. Lakin önerilen denklem sisteminin uygun olabilmesi için modellenmek istenen sistemi çok iyi temsil etmesi ve dinamiklerini iyi yakalaması gerekmektedir. Bunun için tasarımcının sistemi iyi tanıması gerekmektedir. Özellikle sistemde ölçülebilen/ölçülemeyen, gözlenebilen/gözlenemeyen değişkenlerin belirlenmesi, zamanla değişip değişmediğinin bilinmesi ve bunların tahmin edilmesi gibi bir çok şeyi içeren matematiksel bir model olması gerekmektedir. Lakin bu tip sistemlerin yapay sinir ağı, bulanık model gibi yöntemlerle modellenerek sistemi temsil etmesi, sistemin gelecek davranışlarının kestirilmesi gibi işlemler yapılabilmektedir. Ayrıca bu yöntem sayesinde işlem yükü azalmış ve sistemin farklı bir şekilde yine aynı dinamik davranışları temsil eden matematiksel bir model ile çalışılmıştır. Lakin yapay sinir ağının eğitilmesi direk olarak verilere bağlı olduğu için sistemden olabildiğince fazla veri alınarak yapay sinir ağının eğitilmesi gerekmektedir. Aksi takdirde yapay sinir ağı sistemin farklı dinamiklerini kaçırabilir ve hatta sistemden farklı bir işaret üreterek sistemi temsil edemeyip hatalı sonuçlarda üretebilir. Genel olarak bakıldığında ise yapay sinir ağı uygulamalarında hatanın 'sıfır olması' ya da sıfıra yakın olması istenir. Modelleme açısından bu gerekli bir koşuldur. Lakin farklı uygulamalardan olan kaotik sinyal üreteçlerinde ise yörüngelerin birbirini tekrar etmeyen yani 'rastgele' işaretler olması istenen bir durum olduğu için bu tip uygulamalarda hatanın pek önemi kalmayabilmektedir. Sonuçta olarak, YSA ile modellenen kaotik davranış, gerçek kaotik sistem ile aynı özellikleri ve beklenen davranışı gösterebildiği için birbiri yerine kullanılabilir. Dolayısıyla bu ve 
bunun gibi kaotik davranış gösteren herhangi bir hareket yine görüntü işleme teknikleri ile belirlenip yapay sinir ağı ile modellenebilir ve tekrardan üretilebilir, gelecek çıkışları kestirilebilir veya yerine kullanılabilir.

\section{Kaynaklar}

[1] Pehlivan İ., Yeni kaotik sistemler: elektronik devre gerçeklemeleri, senkronizasyon ve güvenli haberleşme uygulamaları, Doktora Tezi, Fen Bilimleri Enstitüsü, Sakarya Üniversitesi, (2010).

[2] Akkaya S., Pehlivan İ., Akgül A. ve Varan M., Yeni bir kaos tabanlı rasgele sayı üreteci kullanan banka şifrematik cihazı tasarımı ve uygulaması, Gazi Üniversitesi Mühendislik-Mimarlık Fakültesi Dergisi, 33, 3, 1172-1182, (2018)

[3] Kacar S., Wei Z., Akgul A. ve Aricioglu B., A novel 4D chaotic system based on two degrees of freedom nonlinear mechanical system, Zeitschrift für Naturforschung, 73, 595-607, (2018).

[4] Sprott J. C., Chaos and time-series analysis, Oxford University Press, (2003).

[5] Akgul A., Calgan H., Koyuncu I., Pehlivan I. ve Istanbullu A., Chaos-based engineering applications with a 3D chaotic system without equilibrium points," Nonlinear dynamics, 84, 2, 481-495, (2016).

[6] Xu G., Shekofteh Y., Akgul A. ve Li C., ve S. Panahi, A new chaotic system with a self-excited attractor: entropy measurement, signal encryption, and parameter estimation, Entropy, 20, 2, 86, (2018).

[7] Camacho E. F. ve Alba C. B., Model predictive control, Springer Science \& Business Media, (2013).

[8] Kis G., Jako Z., Kennedy M., ve Kolumbán G., Chaotic communications without synchronization, (1998).

[9] Akgul A., Moroz I., Pehlivan I. ve Vaidyanathan S., A new four-scroll chaotic attractor and its engineering applications, Optik-International Journal for Light and Electron Optics, 127, 5491-5499, (2016).

[10] Wolf A., Swift J. B., Swinney H. L. ve Vastano J. A., Determining Lyapunov exponents from a time series, Physica D: Nonlinear Phenomena, 16, 285-317, (1985).

[11] Pamuk N., Dinamik Sistemlerde Kaotik Zaman Dizilerinin Tespiti, Balıkesir Üniversitesi Fen Bilimleri Enstitüsü Dergisi, 15, 1, 78-92, (2013).

[12] Lai Q., Akgul A., Li C., Xu G. ve U. Cavusoglu, A new chaotic system with multiple attractors: dynamic analysis, circuit realization and S-box design, Entropy, 20, 12, (2017).

[13] Varan M. ve Akgul A., Control and synchronisation of a novel sevendimensional hyperchaotic system with active control, Pramana, 90, 54, (2018).

[14] Maguire L.P., Roche B., McGinnity T.M. ve McDaid L.J., Predicting a chaotic time series using a fuzzy neural network, Information Sciences, 112, 1-4, 125136, (1998).

[15] Principe J.C., Rathie A. ve Kuo J.M., Prediction of chaotic time series with neural networks, International Journal of Bifurcation and Chaos, 2, 4, 989996, (1992).

[16] Gómez-Gil, P., Ramírez-Cortes, J. M., Hernández, S. E. P. ve Alarcón-Aquino, V., A Neural network scheme for long-term forecasting of chaotic time series, Neural Processing Letters, 33, 215-233, (2011). 
[17] Firat U., Kaotik zaman serilerinin yapay sinir ağlarıyla kestirimi: Deprem verisi durumu, Yüksel Lisans Tezi, Yıldız Teknik Üniversitesi, Fen Bilimleri Enstitüsü, İstanbul, (2006).

[18] Hanbay D., Türkoğlu İ. ve Demir Y., Chua Devresinin Yapay Sinir Ağı ile Modellenmesi, Furat Üniversitesi Fen ve Mühendislik Bilimleri Dergisi, 19, 1, 67-72, (2007).

[19] Panahi S., Aram Z., Jafari S., Ma J. ve Sprott J., Modeling of epilepsy based on chaotic artificial neural network, Chaos, Solitons \& Fractals, 105, 150-156, (2017).

[20] Köker R., Öz C. ve Sarı Y., Hareketli cisimlerin bilgisayar görmesine dayalı hareket analizi, Elektrik-Elektronik-Bilgisayar Mühendisliği 9. Ulusal Kongresi, 497-500, (2001).

[21] Karakaya F., Altun H., ve Çavuşlu M. A., Gerçek zamanlı nesne tanıma uygulamaları için HOG algoritmasının FPGA tabanlı gömülü sistem uyarlaması, IEEE 17th Signal Processing and Communications Applications Conference (SIU), (2009).

[22] Solak S. ve Altınışık U., Görüntü işleme teknikleri ve kümeleme yöntemleri kullanılarak findık meyvesinin tespit ve sinıflandırılması, Sakarya University Journal of Science, 22, 56-65, (2018).

[23] Varol A. ve Cebe B., Yüz tanima algoritmaları, 5th International Computer \& Instructional Technologies Symposium, (2011).

[24] Çelik E., Görüntü İşlemeye dayalı avuç içi izinin yapay sinir ağı ile tanınması, Yüksel Lisans Tezi, Kırıkkale Üniversitesi, Fen Bilimleri Enstitüsü, Kırıkkale, (2014).

[25] Sütçüler E., Gerçek zamanlı video görüntülerinden yüz bulma ve tanıma sistemi, Yüksel Lisans Tezi, Yıldız Teknik Üniversitesi, Fen Bilimleri Enstitüsü, İstanbul, (2006). 